\title{
Evaluation of the effects of Microwave Diathermy in Patients with Chronic Low Back Pain
}

\author{
FARZANA KHAN SHOMA ${ }^{1}$, AZM MAHFUZUR RAHMAN ${ }^{2}$, TARIQUL ISLAM ${ }^{3}$, MD. AHSAN HABIB ${ }^{3}$, \\ KHURSHID MAHMOOD ${ }^{2}$, MD. SHAHIDUL HOSSAIN²
}

\begin{abstract}
:
Background: Back pain affects $60-80 \%$ of people at some time in their lives. Back pain is the most common cause of sickness-related work absence. Microwave diathermy could be an important treatment modality. Very few studies have been conducted in our country in this regard.
\end{abstract}

\begin{abstract}
Aims: To determine the effects of microwave diathermy in relieving symptoms of chronic low back pain when applied along with other conventional therapies like drug and exercise.

Methods: Total 50 patients with chronic low back pain coming to OPD, DMCH were divided randomly into two groups and treated with nonsteroidal anti-inflammatory drugs, exercises, activities of daily living instructions and with or without microwave diathermy. Thereafter, the patients were evaluated weekly. After six weeks of treatment, improvements were observed in both the groups
\end{abstract}

Results: significant difference $(P=0)$ in improvement was found in microwave diathermy group than in non-diathermy group

Conclusion: This study suggests that microwave diathermy is effective in treatment of patients with chronic low back pain.

Introduction:

Low back pain is a symptom complex which affects the area between the lower rib cage and gluteal folds. It is chronic low back pain if it persists for more than three months ${ }^{1}$. Back pain affects 60 $80 \%$ of people at some time in their lives ${ }^{2,3}$. Most patients have short attacks of pain that are mild or moderate and do not limit activities, but these tend to recur over many years. Most episodes resolve with or without treatment. However, a small percentage of low back pain becomes chronic and causes significant disability ${ }^{2}$. In Western countries, back pain is the most common cause of sickness-related work absence and in the UK $7 \%$ of adults consults their GP each year with back pain ${ }^{1}$.

Significant immediate pain relief can be afforded by different therapeutic heating modalities. The proposed mechanisms include an increase in nerve conduction velocity, which may contribute to the reduced pain perception that occurs in response to increasing tissue temperature. In addition, heat contribute to reduction in muscle spasm and also reduction in ischemia as a result of vasodilatation ${ }^{4}$.

Microwave diathermy is a physical therapy modality that produces deep heating via conversion of electromagnetic energy to thermal energy. Thermal energy is produced by increased kinetic energy of molecules within the microwave Weld. Federal Communications Commission approved frequencies for therapeutic microwave are 915-MHz (wavelength $33 \mathrm{~cm}$ ) and 2,456 MHz (wavelength $12 \mathrm{~cm}$ ). Average temperatures of approximately $41^{\circ} \mathrm{C}$ at a depth of $1-3 \mathrm{~cm}$ have been demonstrated ${ }^{2,5}$. Specific contraindications to microwave diathermy can be known to be sensitive to increase cell proliferation rates or skin treated in the past 6 months with radiotherapy, ischemia, local thrombosis or defective arterial circulation, impaired cutaneous thermal sensitivity, metal implants, local infections, and

1. Assistant Professor, Department of Physical Medicine, BIHS

2. Registrar, Surgery, Dhaka Medical College Hospital

3. Medical Officer, Department of Physical Medicine, Bangabandhu Sheikh Mujib Medical University, Dhaka.

4. Assistant Professor, Department of Neurology, Bangabandhu Sheikh Mujib Medical University, Dhaka.

5. Assistant Professor, Department of Physical Medicine, Dhaka Medical College Hospital

6. Assistant Professor, Department of Physical Medicine, Dhaka Medical College Hospital 
indwelling electronic equipment, e.g., pumps or cardiac pacemakers ${ }^{6}$. In our study, we utilized 2456-MHz applicators available in the Physical Medicine and Rehabilitation department of Dhaka Medical College Hospital.

Considering the burden of patients attending the Physical Medicine departments and clinics of different government and private medical facilities in Bangladesh with significant low back pain, the conducted studies on this topic to date in the context of a Bangladeshi population appears to be much fewer than adequate. Although multiple high-quality studies have found that exercise results in positive outcomes in the treatment of chronic low back pain².

\section{Aims:}

The aim of this study was. To determine the effects of microwave diathermy in relieving symptoms of chronic low back pain when applied along with other conventional therapies like drug and exercise

\section{Materials and Methods:}

A total of fifty subjects (32 females and 18 males, age range $24-76$ years) were enrolled in this study during the period of January 2010 to July 2010. The patients were selected randomly based on the following criteria:

Inclusion criteria: The patients of either sex, aged above 20 years and below 80 years, with complaints of significant chronic low back pain affecting activities of daily living, who consented to participate in the study.

Exclusion criteria: The patients aged below 20 years and above 80 years, having low back pain for less than three months, with traumatic, acute and inflammatory etiology, constant progressive pain, present medical history of tuberculosis, carcinoma or systemic corticosteroid use, systemic upset with any spinal deformity, muscle wasting or progressive neurological signs, patients with any complications as well as those unwilling to give consent were excluded.

The participants were initially examined by the same physician. Sociodemographic data including age (years), weight (kg), height (inch), body mass index (BMI, $\mathrm{kg} / \mathrm{m}^{2}$ ), duration of symptoms (month), job and education levelwere obtained. Clinical evaluation was done giving importance to the musculoskeletal and the nervous system and necessary investigations were done. Data for other variables like pulse (beats/min), blood pressure $(\mathrm{mmHg})$, Hemoglobin ( $\mathrm{g} / \mathrm{dl})$, ESR ( $\mathrm{mm}$ in the $\left.1^{\text {sthr }} \mathrm{h}\right)$, Schober's test etc. were thus obtained. Patient's experience of pain before starting treatment was assessed using the Lattinen test ${ }^{7}$ score (Table I).

Figure 1 presents the overall plan of the study. The patients were divided into one of the two groups: Group A $(n=25)$ served as treatment group and Group B served as control group.

\section{Treatment procedures}

Group A received therapeutic microwave diathermy 15 minutes daily along with isometric back muscle exercises, 25 repetitions twice daily and NSAID in the form of Tenoxicam $20 \mathrm{mg}$ once daily for 6 weeks. Group B $(n=25)$ received the same treatment as for group A except that they did not receive microwave diathermy. Normal activities of daily living instructions were advised to both the groups. Therapeutic exercises were demonstrated to the patients of both the groups by the same physiotherapist in the department and patients were advised to continue that at home for the specified duration.

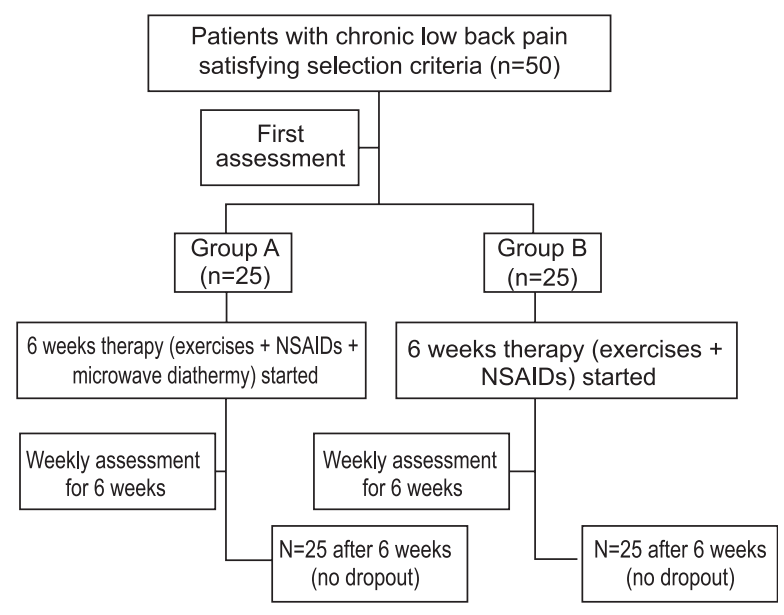

Fig.-1: Plan of the study and Data collection procedures

After the treatment of the patients as per schedule, the patients were followed up weekly for six weeks and the outcomes were recorded in the data collection sheet. Improvement was graded Lattinen's test score.

\section{Statistical analysis}

IBM SPSS Statistics version 19.0 software package for Windows was used to analyze and present the outcome assessment data and perform statistical tests including the Paired-Samples $\mathrm{T}$ test where required to determine the level of significance. The results were expressed as $P$ value and $P<0.05$ was considered as the cutoff for significance. 
Results:

There was no statistically significant difference for age, sex, BMI, educational level, jobs and duration of symptoms between the groups $(P>0.05)$. Basic clinical examination and baseline investigation findings of both groups were also found to be almost identical.

The treatment response assessed at weekly interval by means of Lattinen test score showed gradual reduction in the test score along with clinical improvement with increasing significance as demonstrated by gradual reduction in $P$ value. Pretreatment combined Lattinen test scores in Group $A=9.76 \pm 4.465$ and in Group $B=9.28 \pm 4.523$. At the end of $6^{\text {th }}$ week, Group A score was $3.20 \pm 4.262$ in comparison to Group B score of $5.52 \pm 5.599$. Treatment failure rate is also $4 \%$ lower with microwave diathermy (Table 2). Improvement of Lattinen test score is also significantly associated with application of microwave diathermy at the end of 6 weeks $(P=0.006)$. As compared to conventional drug therapy and exercise, microwave diathermy significantly retards progression and improves symptoms of chronic low back pain at the end of the six weeks therapy as evidenced by more left shifting of area under curve in Figure 2 in case of GroupA. Left shifting of area under curve also occurs for Group B (Figure $2)$, although to a lesser degree. This denotes a notable fall in Lattinen test score value as compared to the pretreatment value depicted in Figure 1, which was quite similar in both the groups.
Table-I

The Lattinen test ${ }^{7 *}$

\begin{tabular}{lll}
\hline A. Subjective intensity & No pain & 0 \\
& Mild & 1 \\
& Uncomfortable & 2 \\
& Severe & 3 \\
& Unbearable & 4 \\
B. Frequency & Never & 0 \\
& Rare & 1 \\
& Frequent & 2 \\
& Very Frequent & 3 \\
C. Analgesics intake & Continuous & 4 \\
& None & 0 \\
& Occasional & 1 \\
& Moderate & 2 \\
& High consumption & 3 \\
D. Disability due to pain & Too much & 4 \\
& None & 0 \\
& Slight & 1 \\
& Moderate & 2 \\
& Necessary aid & 3 \\
& Total dependence & 4 \\
& Normal & 0 \\
& Sometimes awake & 1 \\
& Many times awake & 2 \\
& Insomnia & 3 \\
& Sedatives needed & 4 \\
\hline
\end{tabular}

*Minimum score: 0; maximum score: 20 . The score from each group of questions should be added $(A-E)$.

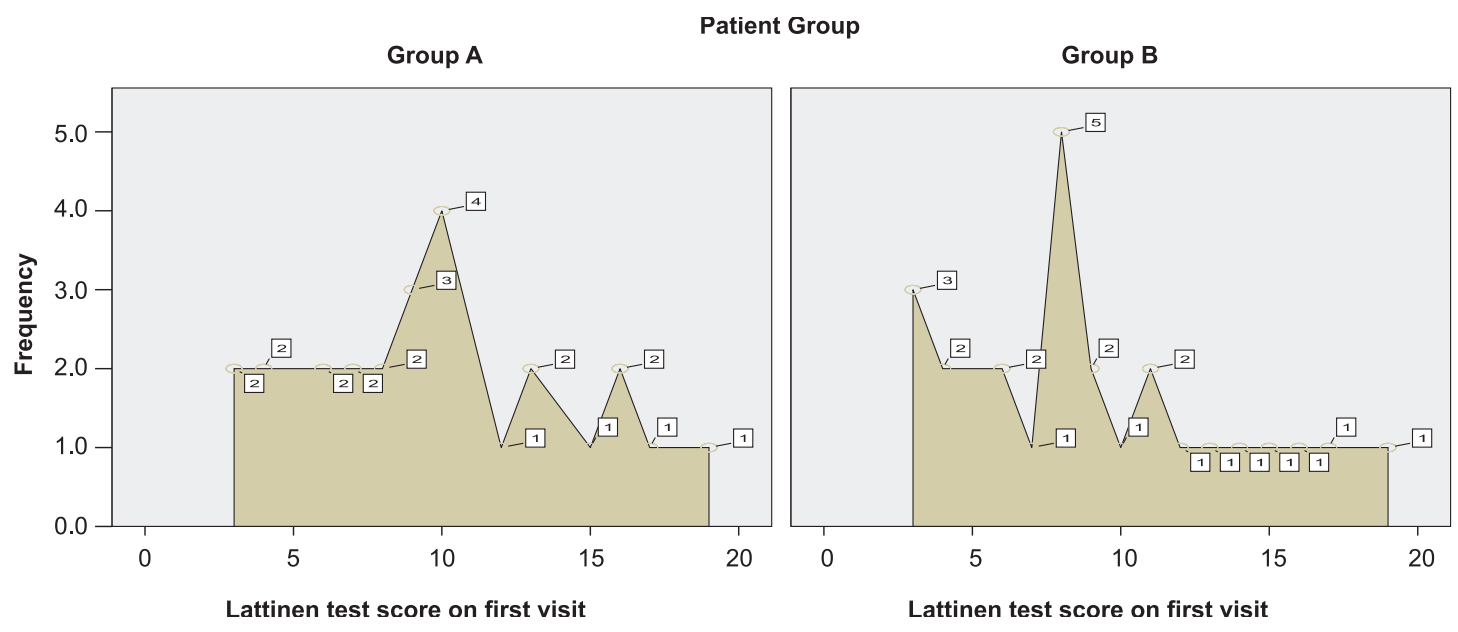

Fig.-2: Graphical correlation of lattinen test score distribution between Group A and Group B before starting therapy. 

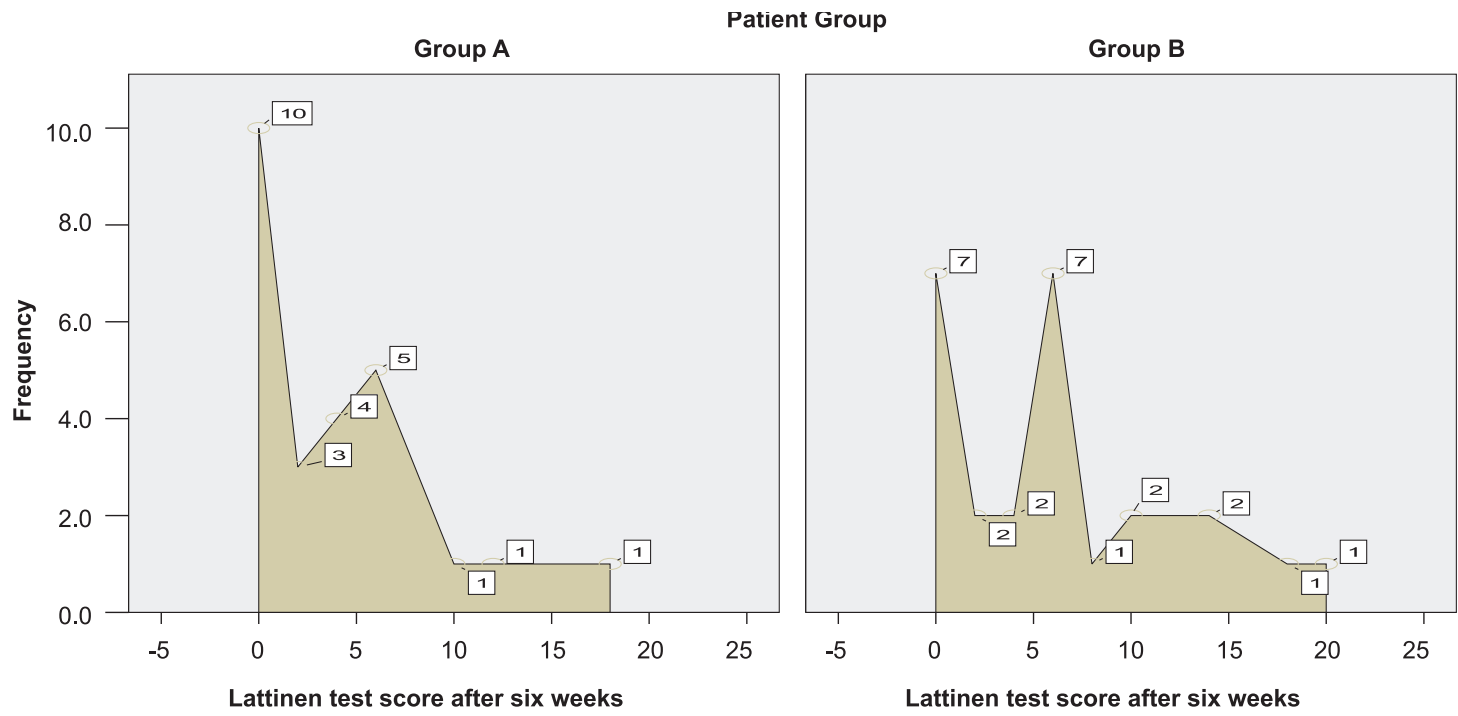

Fig.-3: Graphical correlation of lattinen test score distribution between Group A and Group B after completing therapy.

Table-II

Improvement of Lattinen test score with application of Microwave diathermy

\begin{tabular}{lccccc}
\hline & \multicolumn{4}{c}{ Microwave diathermy given } \\
\cline { 2 - 3 } & \multicolumn{2}{c}{ Yes (Group A) } & & \multicolumn{2}{c}{ No (Group B) } \\
\cline { 2 - 3 } \cline { 5 - 6 } & Count & Column N \% & & Count & Column N \% \\
\hline $\begin{array}{l}\text { Improvement and lower } \\
\text { Lettinen score }\end{array}$ & 24 & $96.0 \%$ & 23 & $92.0 \%$ \\
No improvement & 1 & $4.0 \%$ & & 2 & $8.0 \%$ \\
\hline
\end{tabular}

Discussion:

The present study does not discard existing modality of treatments like exercise and drug therapy when comparing them to microwave diathermy. Rather, it shows that microwave diathermy can be an effective adjunct in improving outcome and to some degree, lessen treatment failure rate. The patients of both groups responded well to the treatment, yet a treatment failure rate of about $10 \%$ was observed in commensurate to standardized data. ${ }^{1} \mathrm{~A}$ steady trends of improvement in symptoms was observed throughout the whole period of six weeks of study. But, in comparison, the significance of improvement in the group of patients who received microwave diathermy was better than that of non-diathermy group $(p=0)$. The outcome of treatment was unrelated to the initial severity or duration of pain of both the groups.

There appears to be a lack of evidence base regarding use of microwave diathermy in the treatment of chronic low back pain, apparent because of the relative paucity of literature on the issue. In their study, $\mathrm{Akyol}^{6}$ et al. found no evidence that true MD, as compared with sham MD, is beneficial when applied in addition to some commonly used interventions, including modalities such as superficial heat and exercises. Multiple researches have been conducted on a related deep heating modality namely shortwave diathermy. Zaman $^{8}$ reported in a study at IPGMR that partial or complete relief of pain was more in the patients who received shortwave diathermy than the 
exercise group or placebo group. Gibson et al. studied 109 patients and significant improvements after treatment were observed in 59\% patients who received shortwave diathermy ${ }^{9}$. Shakoor et al. found that there was significant improvement after giving shortwave diathermy on the patients with neck pain. ${ }^{10}$ In a meticulous review, Chard and Dieppe indicated that the use of non-pharmacological interventions shortwave diathermy in osteoarthritis is essential for goodmanagement ${ }^{11}$. Ullah showed that improvement was better in the patients who received shortwave diathermy than that of the patients who were not treated with shortwave diathermy ${ }^{12}$. Kerem and Yigiter studied 60 patients and showed significant improvements in measured parameters in shortwave diathermy group after the treatment ${ }^{13}$. Debsarma in a study showed that deep heat modality is more effective than superficial heat in pain management in chronic low back painpatients ${ }^{14}$.

\section{Conclusion:}

In conclusion, the present study infers that microwave diathermy can be an effective modality in the treatment of the patients with chronic low back pain. However, our effort needs to be clarified with more research works on potential application of microwave diathermy in management of chronic pains.

\section{References:}

1. Doherty M., Ralston S H, Musculoskeletetal disease: In: Davidson's principles \& practices of medicine; Boon NA, Colledge NR, Walker BR (eds). Edinburgh Churchill Livingstone, 2010, pp1072-4

2. Weber DC, Hoppe KM. Low back pain. In: Physical medicine and rehabilitation. Braddom $\mathrm{RL}$ (ed). 3rd ed. China Saunders Elsevier, 2007, pp 872-7.

3. Ahmed MS, Shakoor MA, Khan AA. Evaluation of the effects of shortwave diathermy in patients with chronic low back pain. Bangladesh Med Res Counc Bull 2009; 35: 18-20.

4. Cameron $\mathrm{MH}$. Diathermy: The ideal therapeutic heating modality. Available from: http://regearlife.com/downloads/diathermy-theideal-therapeutic-heating-modality.pdf
5. Basford JR (1993) Physical agents. In: DeLisa JA, Gans BM (eds) Rehabilitation medicine: principles and practice, 2nd edn. Lippincott Company, Philadelphia, pp 404-24

6. Akyol Y, Ulus $\mathrm{Y}$, Durmus D, et al. Effectiveness of microwave diathermy on pain, functional capacity, muscle strength, quality of life, and depression in patients with subacromial impingement syndrome: a randomized placebo-controlled clinical study. Rheumatol Int 2011, 0172-8172, 1-10

7. Ceballos A, Cabezudo L, Bovaira M, et al. Spinal cord stimulation: A possible therapeutic alternative for chronic mesenteric ischemia. Pain 2000; 87: 99-101.

8. Zaman MM. A study on patients with low back pain attending physical medicine and rehabilitation department of IPGM\&R. Dhaka, IPGM\&R, 1992, Dissertation.

9. Gibson T, Grahame R, Harkness J, et al. Controlled comparison of shortwave diathermy treatment with osteopathic treatment in nonspecific low back pain. Lancet 1985; 1 : 1258-60.

10. Shakoor MA, Islam MQ, Zaman MM, et al.. Effects of cervical traction and shortwave diathermy on the patients with neck pain. J Dhaka Med Coll. 2001; 10: 91-5.

11. Chard J, Dieppe P. The case for nonpharmacologic therapy of osteoarthritis. In: Current rheumatology. Cronstein BN (ed). Philadelphia, Current Science, 2001, pp 88-94.

12. Ullah MA. A study on the patients with nonspecific low back pain attending physical medicine department of IPGM\&R, Dhaka. 1998, Dissertation.

13. Kerem M, Yigiter K. Effects of continuous and pulsed shortwave diathermy in low back pain. Pain Cli 2002; 14: 55-9.

14. Debsarma HN. Low back pain management by physical therapy methods in a developing country, India. 9th World Congress on pain, Vienna, 1999, pp 181-7. 